\title{
Molten Globule Precursor States Are Conformationally Correlated to Amyloid Fibrils of Human $\boldsymbol{\beta}$-2-Microglobulin
}

\author{
Lukasz Skora, ${ }^{\dagger}$ Stefan Becker, ${ }^{\dagger}$ and Markus Zweckstetter ${ }^{\star,+, \ddagger}$ \\ Department of NMR-based Structural Biology, Max Planck Institute for Biophysical Chemistry, Am Fassberg 11, \\ 37077 Goettingen, Germany, and DFG Center for the Molecular Physiology of the Brain, \\ 37073 Goettingen, Germany
}

Received January 18, 2010; E-mail: mzwecks@gwdg.de

\begin{abstract}
Misfolding intermediates play a key role in defining aberrant protein aggregation and amyloid formation in more than 15 different human diseases. However, their experimental characterization is challenging due to the transient nature and conformational heterogeneity of the involved states. Here, we demonstrate that direct carbon-detected NMR experiments allow observation, assignment, and structural analysis of molten globule amyloid intermediates that are severely broadened by conformational exchange. The method is used to characterize the structure and dynamics of partially unfolded intermediates of the 99-residue protein $\beta$-2-microglobulin, which is the major component of insoluble aggregates occurring in dialysis-related amyloidosis. Comparison of the conformational properties of the molten globule-like intermediates with levels of deuterium incorporation into amyloid fibrils of $\beta$-2-microglobulin revealed a close relationship between the conformational properties of the metastable intermediates and the $\beta$-sheet-rich insoluble aggregates of $\beta$-2-microglobulin.
\end{abstract}

Misfolding intermediates play a key role in defining aberrant protein aggregation and amyloid formation in more than 15 different human diseases. ${ }^{1,2}$ However, the experimental characterization of the conformation of amyloid intermediates is challenging due to their transient nature and conformational heterogeneity. ${ }^{3,4}$ This severely limits our knowledge about the relation of the conformation of the precursor states to the structure of amyloid fibrils.

Dialysis-related amyloidosis is a protein misfolding disease resulting from deposition of amyloid aggregates in skeletal tissue that contain fibrils of the 99-residue-long protein $\beta$-2-microglobulin (b2m). ${ }^{5}$ Amyloid formation of $\mathrm{b} 2 \mathrm{~m}$ is strongly enhanced in conditions that destabilize its globular structure. ${ }^{6}$ This can be achieved in vitro by acid denaturation, with two distinct intermediate states being formed under acidic conditions. The highest population of the partially unfolded intermediate occurs at $\mathrm{pH}$ 3.6, where also the rate of fibril formation reaches a maximum. ${ }^{7}$ However, long and straight amyloid fibrils resembling those extracted from patients are formed from a precursor state formed at $\mathrm{pH} 2.5 .^{8,9}$ Here, we compare the conformational properties of these two partially unfolded intermediates with single-residue resolution and demonstrate that a close relationship exists between the structure and dynamics of the amyloid precursor species and the morphology of mature fibrils of $\mathrm{b} 2 \mathrm{~m}$.

At $\mathrm{pH} 2.5 \mathrm{~b} 2 \mathrm{~m}$ is highly unfolded, the majority of resonances are observed in ${ }^{1} \mathrm{H}-{ }^{15} \mathrm{~N}$ HSQC spectra (Supporting Information,

\footnotetext{
\ax Planck Institute for Biophysical Chemistry.

* DFG Center for the Molecular Physiology of the Brain.
}

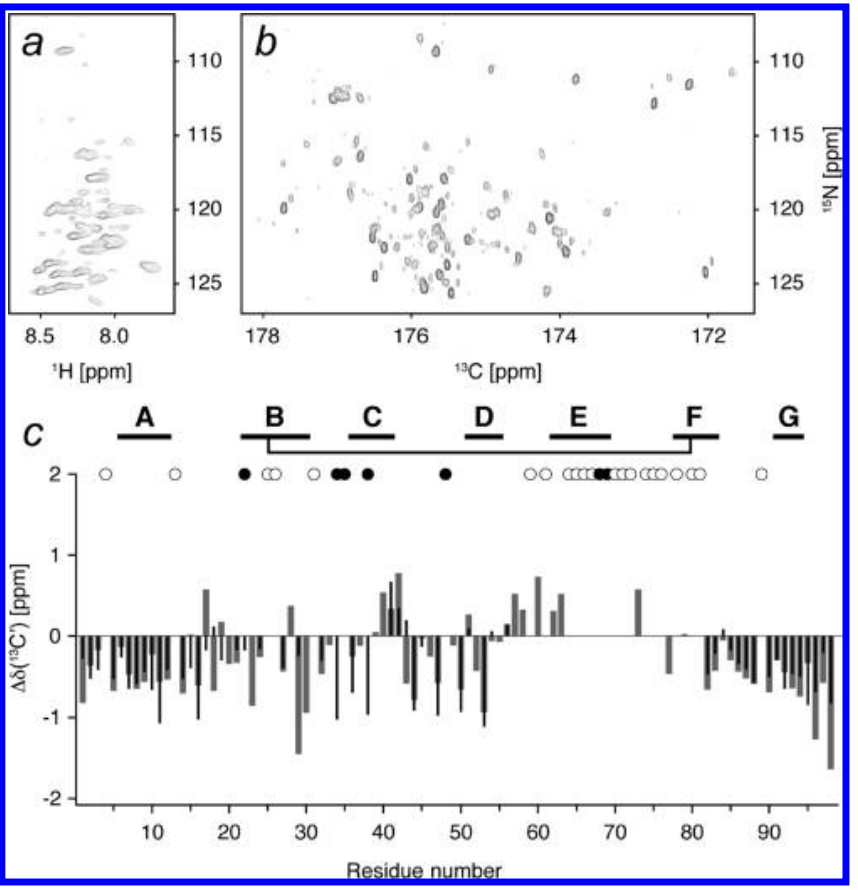

Figure 1. (a) Two-dimensional (2D) ${ }^{1} \mathrm{H}-{ }^{15} \mathrm{~N}$ HSQC and (b) direct carbondetected $\mathrm{CON}$ spectra of $\mathrm{b} 2 \mathrm{~m}$ at $\mathrm{pH} 3.6$. (c) Secondary ${ }^{13} \mathrm{C}^{\prime}$ (gray) and ${ }^{13} \mathrm{C}^{\alpha}$ (black) chemical shifts of $\mathrm{b} 2 \mathrm{~m}$ at $\mathrm{pH} 3.6$; exchange-broadened resonances are marked by open circles; filled circles indicate resonances observable at $\mathrm{pH} 2.5$ but not at $\mathrm{pH} 3.6$; black bars above the plot indicate the location of $\beta$-strands in the native fold.

Figure 1) and can be assigned to individual residues. ${ }^{10}$ In contrast, only about 40-60 resolved peaks on top of a broad hump of unresolved signal intensity (visible at lower contour levels) could be observed at pH 3.6 (Figure 1a). ${ }^{11}$ To obtain sequence-specific information about the $\mathrm{pH} 3.6$ intermediate, we tested direct ${ }^{13} \mathrm{C}$ detection. ${ }^{12-14}$ Direct carbon detection was previously successfully used for the study of unfolded proteins and to alleviate problems of exchange. ${ }^{15-18}$ Strikingly, out of 94 nonproline residues, about 90 resolved signals were observed in a two-dimensional (2D) ${ }^{13} \mathrm{C}$ CON spectrum (Figure 1b). Resonances in this spectrum had very different line-widths (Figure 1), suggesting that the $\mathrm{pH} 3.6$ intermediate contains nonrandom structure. Assignment of resonances was achieved by a combination of ${ }^{1} \mathrm{H}$ - and ${ }^{13} \mathrm{C}$-detected experiments: backbone resonances were assigned at $\mathrm{pH} 2.5 \mathrm{using}$ ${ }^{1} \mathrm{H}$-detected triple-resonance NMR experiments, the assignment was transferred to the $2 \mathrm{D}{ }^{13} \mathrm{C} \mathrm{CON}$ spectrum at $\mathrm{pH} 2.5$, followed by a series of CON and CACO spectra from 2.5 to 3.6, in which chemical shift changes were monitored (Supporting Information, Figure 2). Using this strategy $>75 \%$ of backbone resonances of the intermediate at $\mathrm{pH} 3.6$ were assigned (Supporting Information, 


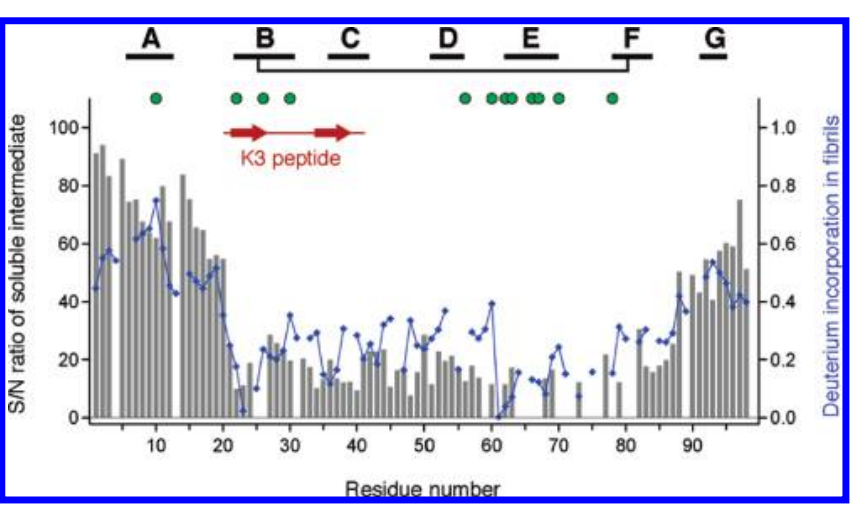

Figure 2. Comparison of signal intensities observed in a 2D CON spectrum for the intermediate at $\mathrm{pH} 2.5$ (gray bars) with the levels of deuterium incorporation in amyloid fibrils of b2m (blue); black bars above the plot indicate the location of $\beta$-strands in the native fold; green circles indicate the location of hydrophobic residues; $\beta$-strands observed in amyloid fibrils of the $\mathrm{K} 3$ peptide are indicated in red.

Figure 3). An overall decrease in intensities was observed at $\mathrm{pH} \approx$ 3.1. The pI of free aspartates and glutamates is 3.9 and 4.3, respectively, but hydrogen bonds are known to depress their $\mathrm{p} K_{\mathrm{a}}$. Thus, the structural transition might be related to the protonation of aspartate and glutamate and the formation of salt bridges. However, there is currently no other evidence for the formation of salt bridges in $\mathrm{b} 2 \mathrm{~m}$.

Sequence-specific assignment of carbonyl carbon chemical shifts allowed characterization of the secondary structure of the amyloid precursor of $\mathrm{b} 2 \mathrm{~m}$ at $\mathrm{pH} 3.6$ with single-residue resolution. Regions $1-33,43-53$, and $82-99$ have a propensity for extended structure, while residues $40-42$ and $57-63$ preferentially populate turn- or helix-like conformations (Figure 1c). In the region 65-82 chemical shift information could only be gained for residues 74,78 , and 79 due to severe exchange broadening even in ${ }^{13} \mathrm{C}$-detected experiments. A comparison between chemical shifts at pH 3.6 and 2.5 (Supporting Information, Figure 4) reveals a higher propensity for extended structure for residues $90-96$ at $\mathrm{pH} 3.6$, while it is reduced for residues 34-40, 45-48, 53-63, and 79-87. Interestingly, downfield shifts (less extended or more $\alpha$-helical or turn propensity) were seen for residues 63 and 79 located in the region most strongly affected by chemical exchange, suggesting that structural differences between the two intermediate states are present in this region. In addition, comparison of peak intensities in the ${ }^{13} \mathrm{C} C O N$ experiment between the two precursors (Supporting Information, Figure 5) shows an overall decrease of signal intensity in the $\mathrm{pH} 3.6$ intermediate, especially in the C-terminal region $82-98$, in agreement with the highest population of the intermediate at $\mathrm{pH}$ 3.6. Noteworthy, truncation of b2m after residue 83 impairs aggregation. ${ }^{19}$

To gain insight into the correlation between the conformational properties of the precursors with the morphology of resulting amyloid fibrils (Supporting Information, Figure 6), we determined the amide hydrogen/deuterium (H/D) exchange profile of amyloid fibrils of b2m at $\mathrm{pH} 2.5$ using NMR spectroscopy. Fibrils formed in $\mathrm{H}_{2} \mathrm{O}$ were subjected to solvent exchange in $\mathrm{D}_{2} \mathrm{O}$ for 7 days at 4 ${ }^{\circ} \mathrm{C}$, pD 2.5. Accordingly, regions protected from solvent exchange are expected to have lower levels of deuterium incorporation. Importantly, dissolution of the amyloid fibrils by $4 \mathrm{M}$ guanidinium thiocyanate in $50 \% \mathrm{H}_{2} \mathrm{O} / \mathrm{D}_{2} \mathrm{O}$ enabled observation of almost all residues (Figure 2), including residues which are part of the disulfide-bridged strands $\mathrm{B}$ and $\mathrm{F}$ in the native structure that were not detected in previous H/D exchange experiments. ${ }^{20}$ Our data show that parts of strands $\mathrm{B}$ and $\mathrm{F}$ stay protected from solvent exchange and are buried in the fibrillar core. Importantly, reduction of the disulfide bridge leads to formation of fibrils with different morphology. ${ }^{10}$

A very good correlation was found between the solvent protection pattern of the fibrils and the exchange broadening of the molten globule-like intermediate represented by signal intensities in the carbon-detected spectra (Figure 2): (i) residues 1-20 and 88-99 are least protected in amyloid fibrils of $\mathrm{b} 2 \mathrm{~m}$ and show the highest signal intensities in the $\mathrm{pH} 2.5^{20}$ as well as $\mathrm{pH} 3.6$ precursor (Figures 1 and 2); (ii) residues 29-34 and 38-60 have intermediate solvent exposure in the fibrils and have intermediate signal intensities in the spectrum of the intermediate; (iii) residues $22-25$, 35-37, 61-68 and 72-78 show the lowest levels of deuterium incorporation in the fibrils and have low signal intensities or are broadened beyond detection in the ${ }^{13} \mathrm{C} \mathrm{CON}$ experiment. Increased chemical exchange was previously reported for residues $20-80$ in the $\mathrm{b} 2 \mathrm{~m}$ intermediate at $\mathrm{pH} 2.5 .^{10}$ Many hydrophobic residues are found in these regions, and mutagenesis experiments designed to decrease the hydrophobicity resulted in slower aggregation kinetics, ${ }^{19,21}$ suggesting the formation of hydrophobic clusters. Two peptides (residues 21-40, the so-called K3 peptide, and residues 59-71), which overlap with the regions that are strongly exchange broadened in the $\mathrm{pH} 3.6$ intermediate, were reported to self-associate in vitro. ${ }^{22,23}$ The two $\beta$-strands (residues $21-28$ and 33-40) observed in amyloid fibrils of the K3 peptide ${ }^{24}$ match the two minima in the H/D exchange profile (Figure 2), suggesting that amyloid fibrils of full-length $\mathrm{b} 2 \mathrm{~m}$ also contain two $\beta$-strands in this region.

We demonstrated that signals of partially unfolded intermediate ensembles broadened due to conformational exchange can be structurally characterized using direct carbon-detected NMR experiments. Comparison between the structural and dynamic properties of the amyloid intermediate of $\mathrm{b} 2 \mathrm{~m}$ with H/D exchange measurements on amyloid fibrils revealed a close relationship between the conformational properties of the metastable partially unfolded precursor and the $\beta$-sheet-rich insoluble aggregates of a diseaserelevant protein that assumes a rigid 3D fold in its native state.

Acknowledgment. We thank S. Xiang for HSQC measurements and Max Planck Society and DFG (ZW 71/2-2 and 3-2 to M.Z.).

Supporting Information Available: ${ }^{1} \mathrm{H}-{ }^{15} \mathrm{~N}$ HSQCs, signal intensities, and secondary chemical shifts at $\mathrm{pH} 3.6$ and 2.5; electron micrographs of $\mathrm{b} 2 \mathrm{~m}$ fibrils. This material is available free of charge via the Internet at http://pubs.acs.org.

\section{References}

(1) Kisilevsky, R. Nat. Med. 2000, 6, 633-634.

(2) Horwich, A. J. Clin. Invest. 2002, 110, 1221-1232.

(3) Brockwell, D. J.; Radford, S. E. Curr. Opin. Struct. Biol. 2007, 17, 30-37.

(4) Ferreira, S. T.; De Felice, F. G.; Chapeaurouge, A. Cell Biochem. Biophys. 2006, 44, 539-548.

(5) Gejyo, F.; Yamada, T.; Odani, S.; Nakagawa, Y.; Arakawa, M.; Kunitomo, T.; Kataoka, H.; Suzuki, M.; Hirasawa, Y.; Shirahama, T. Biochem. Biophvs. Res. Commun. 1985, 129, 701-706.

(6) Chiti, F.; De Lorenzi, E.; Grossi, S.; Mangione, P.; Giorgetti, S.; Caccialanza, G.; Dobson, C. M.; Merlini, G.; Ramponi, G.; Bellotti, V. J. Biol. Chem. 2001, 276, 46714-46721.

(7) McParland, V. J.; Kad, N. M.; Kalverda, A. P.; Brown, A.; Kirwin-Jones, P.; Hunter, M. G.; Sunde, M.; Radford, S. E. Biochemistry 2000, 39, 87358746.

(8) Naiki, H.; Hashimoto, N.; Suzuki, S.; Kimura, H.; Nakakuki, K.; Gejyo, F. Amyloid Int. J. Exp. Clin. Invest. 1997, 4, 223-232.

(9) Yamaguchi, I.; Hasegawa, K.; Naiki, H.; Mitsu, T.; Matuo, Y.; Gejyo, F. Amyloid 2001, 8, 30-40.

(10) Katou, H.; Kanno, T.; Hoshino, M.; Hagihara, Y.; Tanaka, H.; Kawai, T.; Hasegawa, K.; Naiki, H.; Goto, Y. Protein Sci. 2002, 11, 2218-2229.

(11) McParland, V. J.; Kalverda, A. P.; Homans, S. W.; Radford, S. E. Nat. Struct. Biol. 2002, 9, 326-331.

(12) Bermel, W.; Bertini, I.; Felli, I. C.; Lee, Y. M.; Luchinat, C.; Pierattelli, R. J. Am. Chem. Soc. 2006, 128, 3918-3919. 
(13) Bermel, W.; Bertini, I.; Felli, I. C.; Kummerle, R.; Pierattelli, R. J. Magn. Reson. 2006, 178, 56-64.

(14) Bermel, W.; Bertini, I.; Duma, L.; Felli, I. C.; Emsley, L.; Pierattelli, R.; Vasos, P. R. Angew. Chem., Int. Ed. 2005, 44, 3089-3092.

(15) Bermel, W.; Bertini, I.; Felli, I. C.; Kummerle, R.; Pierattelli, R. J. Am. Chem. Soc. 2003, 125, 16423-16429.

(16) Oh, B. H.; Westler, W. M.; Darba, P.; Markley, J. L. Science 1988, 240 , 908-911.

(17) Bermel, W.; Bertini, I.; Felli, I. C.; Piccioli, M.; Pierattelli, R. Prog. Nucl. Magn. Reson. Spectrosc. 2006, 48, 25-45.

(18) Hsu, S. T.; Bertoncini, C. W.; Dobson, C. M. J. Am. Chem. Soc. 2009, $131,7222-7223$.

(19) Routledge, K. E.; Tartaglia, G. G.; Platt, G. W.; Vendruscolo, M.; Radford, S. E. J. Mol. Biol. 2009, 389, 776-786.
(20) Hoshino, M.; Katou, H.; Hagihara, Y.; Hasegawa, K.; Naiki, H.; Goto, Y. Nat. Struct. Biol. 2002, 9, 332-336.

(21) Platt, G. W.; Routledge, K. E.; Homans, S. W.; Radford, S. E. J. Mol. Biol. 2008, 378, 251-263.

(22) Kozhukh, G. V.; Hagihara, Y.; Kawakami, T.; Hasegawa, K.; Naiki, H.; Goto, Y. J. Biol. Chem. 2002, 277, 1310-1315.

(23) Jones, S.; Manning, J.; Kad, N. M.; Radford, S. E. J. Mol. Biol. 2003, 325, 249-257.

(24) Iwata, K.; Fujiwara, T.; Matsuki, Y.; Akutsu, H.; Takahashi, S.; Naiki, H.; Goto, Y. Proc. Natl. Acad. Sci. U.S.A. 2006, 103, 18119-18124.

JA100453E 